\title{
Role of enzyme activity in increasing soybean plants' resistance to herbicides
}

\author{
Valentina Sinegovskaya*, and Oksana Dushko \\ FSBSI FSC "All-Russian Scientific Research Institute of Soybean", 675027 Blagoveshchensk, \\ Russian Federation
}

\begin{abstract}
The article presents the study results of specific activity and multiple forms of peroxidase and catalase as antioxidant enzymes in leaves and seeds of Garmoniya soybean variety in oxidative stress conditions caused by herbicides. It has been found that herbicides not only destroy weeds, but also have an effect on cultivated plants. Significantly low specific peroxidase activity in soybean leaves was identified in crops treated with Pulsar herbicide. High specific peroxidase activity and increased number of multiple forms (14) in soybean leaves was caused by Pivot herbicide exceeding control by almost three times, which was confirmed by a slowdown in growth and development of soybean plants by reducing the intensity of growth processes and, accordingly, increasing their resistance to withstanding adverse conditions caused by exposure to chemical substances - herbicides. Analysis of specific activity and multiple forms of catalase in soybean seeds of the 2018 and 2019 harvest showed differences in enzyme activity and number of forms depending on the herbicides used. Changes in enzymes' activity and the number of their forms indicate a change in metabolic processes occurring when using herbicides depending on their chemical nature, which provides plant resistance to stress.
\end{abstract}

\section{Introduction}

In the early stages of soybean plants' development, they are characterized by slow growth and low competitiveness in relation to weeds [1,2]. In the development process between cultivated and weed plants there is a struggle for moisture, nutrients, solar energy, and therefore, resistance to adverse environmental factors is weakened. In addition, weedy plants are inhabited by harmful insects that spread disease to cultivated plants, resulting in a $35-83 \%$ reduction in yields $[3,4]$. In the fight against weed, chemical defense means occupy almost the first place, ahead of others, including biological [5]. For the destruction of weeds in agricultural crops, wide spectrum herbicides are used, but they affect plants selectively: some of them can inhibit growth and development, and others - in residual quantities - stimulate physiological processes. For example, as a result of crops' treatment with Pivot and Pulsar herbicides, soybean leaves briefly get lighter, the growth and

\footnotetext{
*Corresponding author: valsin09@gmail.com
} 
development of plants is suspended for an average of 7 days depending on the variety and growth conditions [6]. In the process of prolonged use of the same herbicides, there is resistance of cultivated plants formed to them. In assessing the resistance degree of agricultural plants to adverse environmental factors, some researchers use biologically active substances, micro fertilizers, biological means of protection, growth regulators, which is determined by the harvest amount, chemical composition and quality of seeds [79]. Thus, the positive influence of wheat crops treatment by modern herbicides on the indicators of plant growth, gluten quality and gluten proteins content [10] was revealed. Other studies found an increase in the germination energy of soybean seeds by $5 \%$, and yield - by $0,25 \mathrm{t} / \mathrm{ha}$ when using biological preparations Betulin and ExtraKor together with herbicides [11]. The resistance of crops to herbicides is also studied by enzyme activity indicators, which naturally bear the role in maintaining metabolism constancy during the period of exposure to various negative factors [12,13]. Enzymes that cause reaction to external factors and play a key role in the use of active oxygen forms are peroxidase and catalase $[14,15]$. In increasing plants' resistance to adverse environmental factors, a special place belongs to peroxidase [16]. Peroxidases are related to catalases both in structure and function. It is assumed that with stressful conditions and various organ damage, peroxidase activity decreases and catalase's is sharply increased, which is an indicator of plants' adaptability to adverse environmental factors [17]. The role of enzymes in increasing the resistance of plants and soybean seeds to adverse environmental factors caused by exposure to herbicides is poorly studied and is of scientific and practical interest. Therefore, the aim of our research was to study the activity of peroxidases and catalases in soybean leaves and seeds under the action of herbicides causing oxidative stress in plants as an indicator of their resistance to adverse environmental factors.

\section{Materials and methods}

Research was carried out in 2018-2019 in Garmoniya variety soybean plantings on the experimental field of FSBSI FSC RSRI of Soybean located in Sadovoye village in Amur region. The Frontier herbicide was used to control weeds in a dose of $1.2 \mathrm{l} / \mathrm{ha}$, which was introduced by soil placement 2 days before sowing. Herbicides were introduced in the phase of 2-3rd ternate leaf $(\mathrm{V} 3-\mathrm{V} 3)$ in soybean crops: Basagran (2 1/ha) against the background of Frontier soil introduction ( 1.2 1/ha); Pulsar (0.8 1/ha); Pivot (0.7 1/ha); Fabian $(100 \mathrm{~g} / \mathrm{ha})$. For analysis on determining specific activity and multiple forms of enzymes, soybean leaves were selected in the bean formation beginning phase (R3), seeds - in the phase of technical maturity during harvest. The specific peroxidases activity was determined by the colorimetric method according to Boyarkin in modification of Mokronosov [18], specific catalase activity - by gasometric method and expressed in activity units per mg of protein [19]. Electrophoretic spectra of catalases were detected by electrophoresis method on columns of $7.5 \%$ polyacrylamide gel [20].

\section{Results and discussion}

Under the influence of herbicides, the formation of active oxygen forms increases leading to excessive oxidative stress in cells. The adaptation of soybeans to the effects of herbicides depends on the activity of the peroxidase enzyme as a marker of oxidative stress. In our experiments, there was a slight decrease in peroxidase activity after soybean crops treatment with herbicides in plant leaves affected by Basagran and Fabian, compared to this indicator in control where herbicides were not used (Figure $1 \mathrm{a}$ ). With this, the number of forms and their electrophoretic mobility was higher relative to control (Figure $1 \mathrm{~b}$ ). 
Significantly low specific peroxidase activity in soybean leaves was identified in crops treated with Pulsar herbicide. The high enzyme activity in soybean leaves was caused by Pivot herbicide, exceeding control by almost three times, which was accompanied by an increase in the number of multiple forms to 14 pcs. and an increase in their mobility.
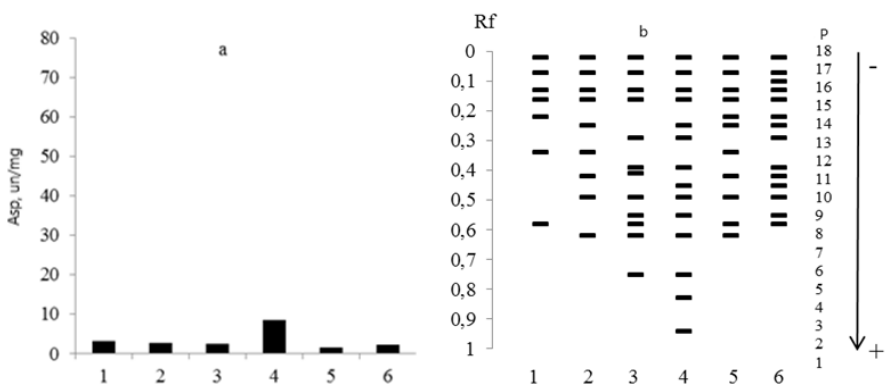

Fig. 1. Specific activity diagram (a) and enzymograms scheme (b) of Garmoniya soybean leaves' peroxidases after application of herbicides: 1 - control (no herbicides), 2 - Frontier to the soil, 3 Frontier + Basagran, $4-$ Pivot, $5-$ Pulsar, $6-$ Fabian. Arrow shows electrophoresis direction from cathode to anode

Increase of specific activity and heterogeneity of peroxidase forms in soybean leaves with Pivot herbicide application indicates a decrease in the growth processes intensity and increase of adaptive soy leaves' potential under the influence of stress caused by this herbicide. Phenotypically, this was manifested in changing leaf color and slowing the growth of soybean plants.

Analyzing the enzymes activity and the number of multiple peroxidase forms in soybean seeds obtained after herbicide application in crops, it is possible to identify the residual amount of herbicide and its active substances in seeds. Specific peroxidase activity in soybean seeds of 2018 and 2019 harvests has changed, both depending on the temperature regime during the research years and the herbicides used (Figure 2).
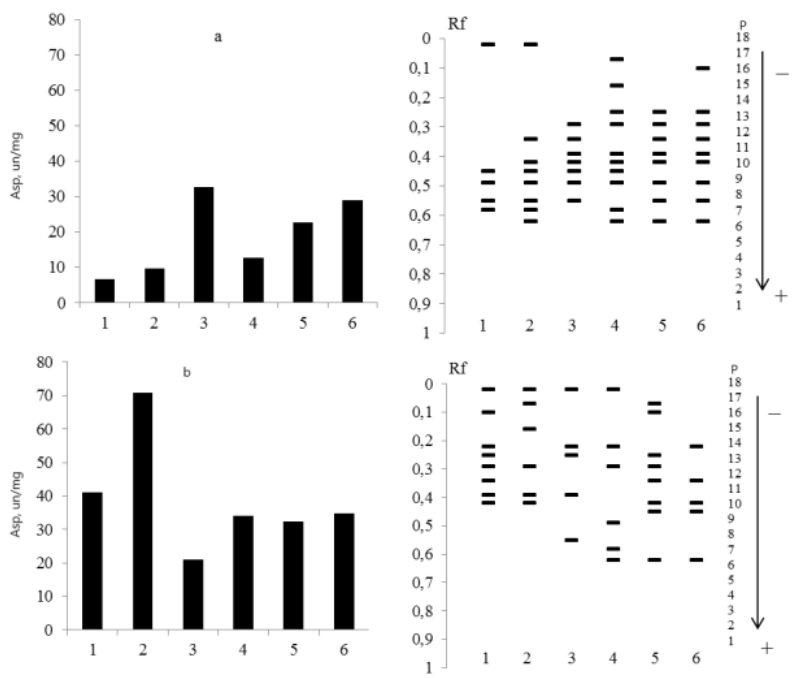

Fig. 2. Specific activity diagram and enzymograms scheme of soybean seeds peroxidases harvests: 2018 (a) and 2019 (b) after the use of herbicides: 1 - control (no herbicides), 2 - Frontier, 3 - Frontier 
+ Basagran, 4 - Pivot, 5 - Pulsar, 6 - Fabian. Arrow shows electrophoresis direction from cathode to anode

The specific peroxidase activity in control samples in soybean seeds of the 2018 harvest was almost six times lower (Figure 2 a) than in the seeds of the 2019 harvest (Figure 2 b). The maximum peroxidase activity was established in the 2019 soybean seeds harvest obtained with the use of only Frontier soil herbicide, which was seven times less than in the seeds of the 2018 harvest. Peroxidase activity varied slightly over the years in seeds obtained by using herbicides at vegetating plants. The influence of Pivot and Pulsar herbicides was equivalent, probably because they belong to one chemical class by the active substance - imidazolinones. The peroxidase enzymogram scheme revealed that the number of enzyme forms in 2018 soybean seeds harvest using herbicides was higher than in the seeds of the 2019 harvest. Inverse relation is observed in control: in soybean seeds of the 2018 harvest, the number of forms is higher than in the seeds of the 2019 harvest, which correlates to the low specific activity of the enzyme.

Along with peroxidase activity, an important indicator of oxidative stress is the activity of the antioxidant enzyme catalase. Specific catalase activity in soybean leaves was low both in control and in crops with the use of Pivot and Pulsar herbicides, which indicates a slight effect on the enzyme activity (Figure 3 a). High activity was detected in soybean leaves in the option using Frontier and Fabian herbicides.

A stable amount (4) of multiple peroxidase forms has been revealed in crops using herbicides. Five forms were observed in the leaves of the control option with four forms with electrophoretic mobility $\mathrm{Rf}=0.42 ; 0.30 ; 0.22$ and 0.08 proved stable (Figure $3 \mathrm{~b}$ ).

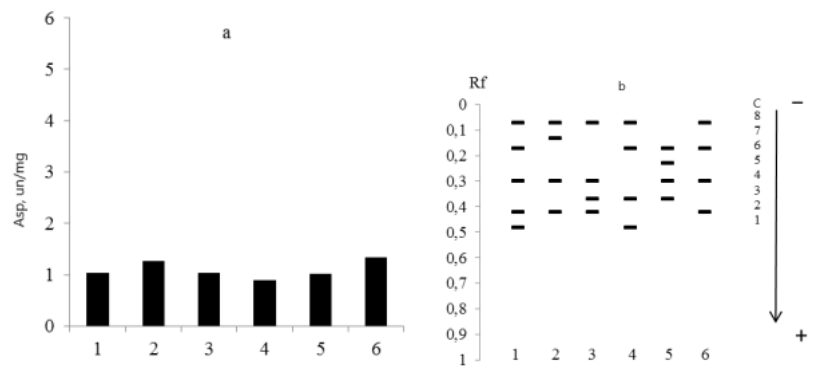

Fig. 3. Specific activity diagram (a) and enzymograms scheme (b) of Garmoniya soybean leaves' catalases after herbicides' application: 1 - control (no herbicides), 2 - Frontier, 3 - Frontier + Basagran, 4 - Pivot, 5 - Pulsar, 6 - Fabian. Arrow shows electrophoresis direction from cathode to anode

Analysis of the activity and number of multiple forms of catalase in soybean seeds of the 2018 and 2019 harvests showed differences in enzyme activity both by year and in experimental options (Figure 4). 

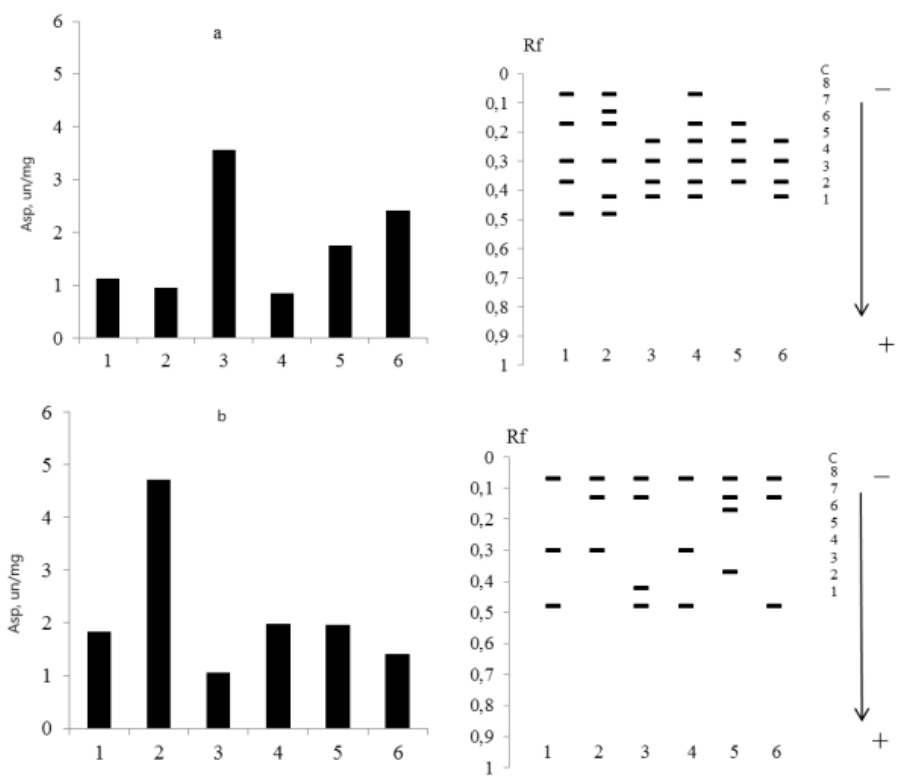

Fig. 4. Specific activity diagrams and enzymogram diagrams of soybean seed catalases: 2018 (a) and 2019 (b) after herbicides' use: 1 - control (no herbicides), 2 - Frontier, 3 - Frontier + Basagran, 4 Pivot, 5 - Pulsar, 6 - Fabian. Arrow shows electrophoresis direction from cathode to anode

The maximum catalase activity in soybean seeds of 2019 harvest was established in the option with Frontier herbicide, which was five times higher than this indicator for 2018 harvest seeds. In 2018, catalase activity was three times higher in soybean seeds with the use of Frontier + Basagran herbicides compared to in the seeds of the same option in 2019. In soybean seeds of the 2018 harvest, the maximum number of mobile enzyme forms was revealed compared to the seeds of the 2019 harvest. It should be noted that in soybean seeds with high specific catalase activity (options with the use of Frontier + Basagran, Fabian, Pulsar herbicides) a low number of enzyme forms was noted, and low enzyme activity, but a high number of forms of this enzyme was revealed in soybean seeds options control, Frontier and Pivot. A form with electrophoretic mobility $\mathrm{Rf}=0.30$ was found in all experimental options in soybean seeds of the 2018 harvest. In all options of the soybean seeds of 2019 harvest, the same form with low electrophoretic mobility was also found - Rf $=0.07$.

\section{Conclusions}

Research results showed that by destroying weeds herbicides affect cultivated plants, which is confirmed by a decrease in peroxidase activity and increased catalase activity under the influence of herbicides used on vegetating soybean plants. Changes in enzymes' activity and the number of their forms indicate a change in metabolic processes occurring when using herbicides depending on their chemical nature, which provides plant resistance to stress caused by chemicals in the form of herbicides. High specific peroxidase activity and an increased number of multiple forms (14) was caused in soybean leaves by Pivot herbicide, exceeding control by nearly three times; this is confirmed by an increase in adaptive potential of Garmoniya soybean variety plants to this herbicide by reducing the intensity of growth processes regulated by enzymes. 


\section{References}

1. Zh.A. Arkova, K.A. Manaenkov, M.S. Koldin et al, Technologies of food and processing industry of AIC - healthy food products, 4, 15 (2017)

2. N.N. Lysenko, Bulletin of Agrarian Science, 2(71), 19 (2018)

3. Sh.B. Bayrambekov, E.D. Garianova, E.G. Kipaeva, Formation and development of agricultural science in the XXI century : coll. of scient. articles, 328 (2016)

4. G Singh, Journal of Agronomi, 77, 675 (2007)

5. V.T. Krasilnikov, Yu.V. Lobachev, International Journal of Experimental Education, 4(12), 528 (2015)

6. A.A. Tsyban'. Abstract of thesis of Candidate of Sciences, 22 (2012)

7. E.A. Dvoryankin, Antidepressants on sugar beet damaged by herbicides, 4, 27 (2019)

8. T. P. Sabirova, AIC Herald of Upper Volga region, 3, 18 (2018)

9. E.V. Klimova, Abstract journal, 3, 734 (2001)

10. E.F. Fadeeva, N.G. Malyshkin, Agrarian Bulletin of Urals, 7(49), 33 (2008)

11. M.P. Mikhailova, V.T. Sinegovskaya, Bulletin of the Russian Agricultural Science, 6, 9 (2019)

12. A. Sofo, A. Scopa, M. Nuzzaci, A. Vitti, Int. J. Mol. Sci, 16, 13561 (2015)

13. N.G. Nesterova, O. V. Voitsekhovskaya, The world of science and innovation, 1(3), 68 (2016)

14. M.S. Sinkevich, A.A. Selivanov, O.V. Antipina et al, Plant Physiology, 63(6), 777 (2016)

15. D.K. Chernyshuk, L.E. Ivachenko, New and unconventional plants and prospects for their use, 12, 87 (2017)

16. L. E. Ivachenko, A. S. Konichev, The role of biologically active soybean substances in adaptation to growing conditions, 154 (2016)

17. M.P. Mikhailova, Agriculture, 1, 47 (2017)

18. A.T. Mokronosova, Small workshop on plant physiology, 184 (1994)

19. B. P. Pleshakov, Workshop on plant biochemistry, 255 (1985)

20. B.J. Davis, Ann. N. Y. Acad. Sci, 121, 404 (1964) 